\title{
Wireless Fuzzy Controller for Drip Irrigation
}

\author{
Dr. Ali Hamouda ${ }^{1}$, Dr. Taj Eldain A.G ${ }^{2}$, Dr. Dia Zayan ${ }^{3}$, Hassan CHaib ${ }^{4}$ \\ Assistant Professor, Dept of Electric and Electronics, Jordanian Sudanese College ${ }^{1,3}$ \\ Assistant Professor, Dept of Electronics and Instrumentation, University of Bahri, Sudan ${ }^{2}$ \\ HSE Lecturer and HSE Senior Trainer, Sadara Institute, Muscat, Sultanate of $\mathrm{Oman}^{4}$
}

\begin{abstract}
This paper cover the design of fuzzy irrigation system based on AVR microcontroller Atmega 32 to design and develop a low cost feature which is based on embedded platform for water irrigation system. The project designed using MATLAB 10, fuzzy logic and Simulink tools books the temperature and soil moisture sensors are used for detect the water quantity present in agriculture and water level sensor used for detecting water level in tank the level gauge interfaced by electronic circuit worked as signal conditioner circuit the water from tanks controlled by solenoid valve which actuated by relay circuit open and close as the microcontroller output then the water transmitted to roots zone using pipes line for irrigation process. The data from plant farms transmitted to control room by wireless networks in which temperature and soil moisture sensors and water level can be monitored and controlled.
\end{abstract}

Keywords: Temperature, Soil Moisture, Sensors, Irrigation System, Wireless Sensor Network (WSN).

\section{INTRODUCTION}

The population growth and environmental change both are the most challenges for the ministry agriculture and the governments, many researchers developed in this area including, foods production, saving water, and reducing the pollution to protects our environments from the pollutions that produced by the man in through industry and energy production. Universities, research center, institute and the governments through the world they published many articles and paper in the field of irrigation management, irrigation control, solar energy, water safety, environmental management and, yields, vegetables and agriculture production management. With the rapid development of agriculture in China, crop growth required Soil moisture content it's the basic of yields growth, while over soil moisture cause the death of crops', and lot of fertilizer which will cause pollution for water and environmental [1]. The development of the electronics technology support the technical application in the field of agriculture by controlling, monitoring of soil moisture content had made great progress [2] A soil moisture detection system based on ZigBee wireless network, and all the references only stated monitoring soil moisture content and had no control function, set up a small farmland data acquisition platform using ZigBee network, and obtained information of the solar energy, wind and current[3]; achieved a remote monitoring of irrigation system through the distributed WSN and GPRS[4]The farmers manually control the water supply by tabulating the irrigation time of the croups. These process not accurate irrigation amounts of water loosed. For this reason an automatic irrigation system based on sensing technology is required to reduce the cost and to give uniformity in water application across the field [5]

Wireless networks technology used in many field of data collection and dad acquisition system because it is reliable data transfer and law cost and energy consumer, by using mat lab or any electronics software simulator, flexible network can de designed. To save the water and controlling irrigation process the wireless and fuzzy logic control system can be used for this process the technology used in many applications that involve monitoring of realtime data. In order to optimize the yield and the use of the available resources, wireless sensor networks can play a relevant role because of their ability of providing real-time data collected by spatially distributed sensors.

\section{IRRIGATION SYSTEM}

Irrigation is the manual application of delivering water for growing crops. Irrigation process is pumping the water from water source to the crops according to the crops need, irrigation system before depending on the farmers expert and manual observation of the crops, with the growth of the technology they are many techniques of irrigation, open channel close channel Surface irrigation, Localized irrigation, Drip irrigation and Sprinkler irrigation. In this paper drip irrigation with irrigation sensor network is used. Two general types of controllers are used to control irrigation systems: Open control loop systems and closed control loop systems. Open control loop systems apply a preset action, such as is done with simple irrigation timers. Closed control loops receive feedback from sensors, make decisions and apply the results of these decisions to the irrigation system, our circuit diagrams consist of microcontroller ATMEGA 32 for controlling the pumps, tanks and solenoid valves, sensor to read temp and another for humidity's. The controlling process monitored with LCD and computer interfaced with the irrigation networks the controller controls valves by sending signal to through the driver to relay circuit witch turn $\mathrm{ON}$ or $\mathrm{OF}$ the valves or motors 
Vol. 6, Issue 1, January 2017

according to the fuzzy logic programs. This type of Then Rules the input of the microcontroller is coming irrigation allows the irrigate at the right time, saving water from the temperature and soil moisture sensors then and improves crop performances.

\section{DATA ACQUISITION SYSTEM}

The data acquisition system required to monitoring over all field in each Green house and then sending the data to control room the data may transferred by wire or wireless network for wireless networks sensor the ZigBee protocols are used. The control system development to using one sensor for both temperature and soil moisture that can be placed on roots zone for monitoring the temperature and moisture of soil, by using feedback control mechanism with a centralized control unit which regulates the flow of water on to the field in the real time based on the instantaneous temperature and moisture values [7]. The proposed Fuzzy logic controller based controller was prototyped using MATLAB. The input parameters like air temperature, soil moisture are tabulated as in figure and the result of different reading used in the design of fuzzy logic controller for drip irrigation system.

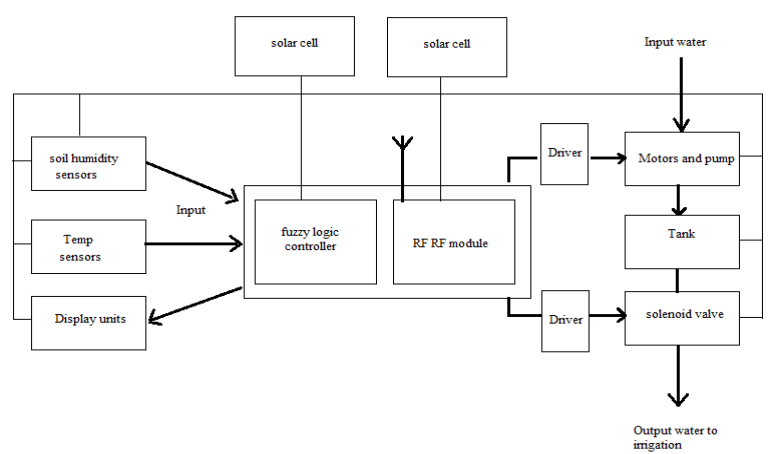

Control circuit block diagrams

\section{FUZZY LOGIC CONTROLLER}

The fuzzy logic irrigation controlled designed and simulated by MATLAB software the proposed role three rules using IF.

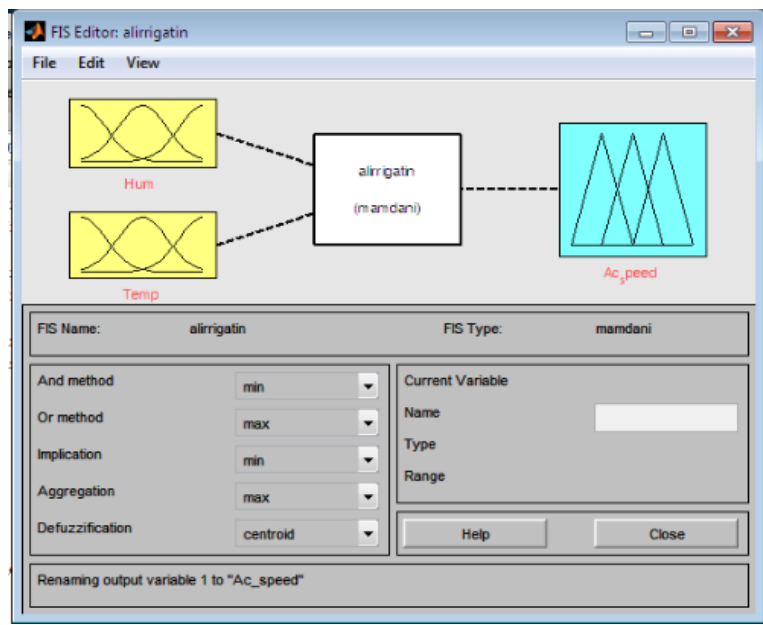

Figure 2. FIS editor compared with inference machine data that stored into the fuzzy controller each step of the design discussed as in the figures.

As in the figure 2. the fuzzy editor is block fund in MATLAB fuzzy logic simulation consist of dour blocks two blocks used for input signal temp and humidity and one for fuzzy controller and the last one used for output of fuzzy irrigation controller.

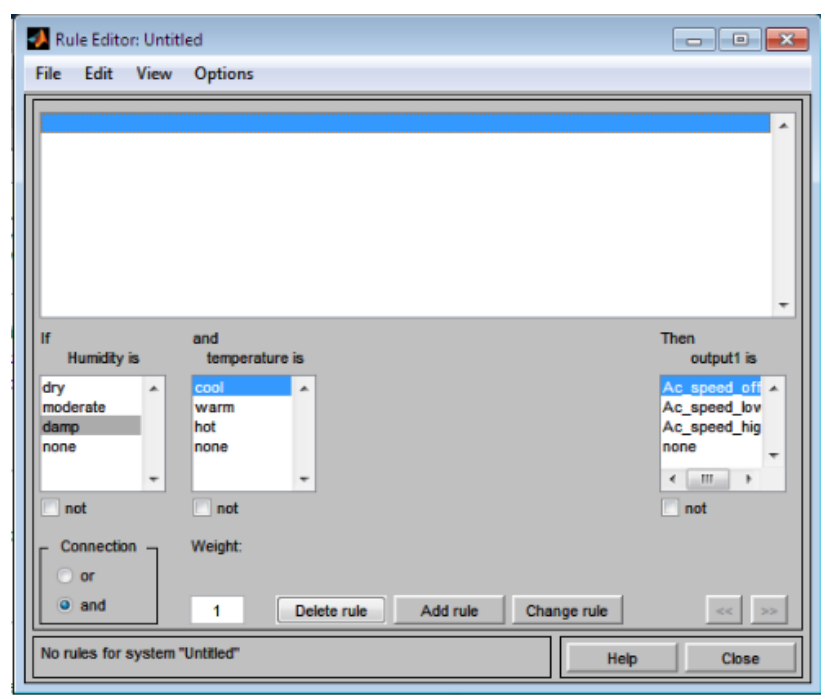

Figure 3. Fuzzy logic rule Editors

Figure 3. Shows the input from the humidity sensor and temperature sensor and the out pout of the controller, the logic can be selected via ANA, OR, NOT logic functions switch can be selected from the rule editor.

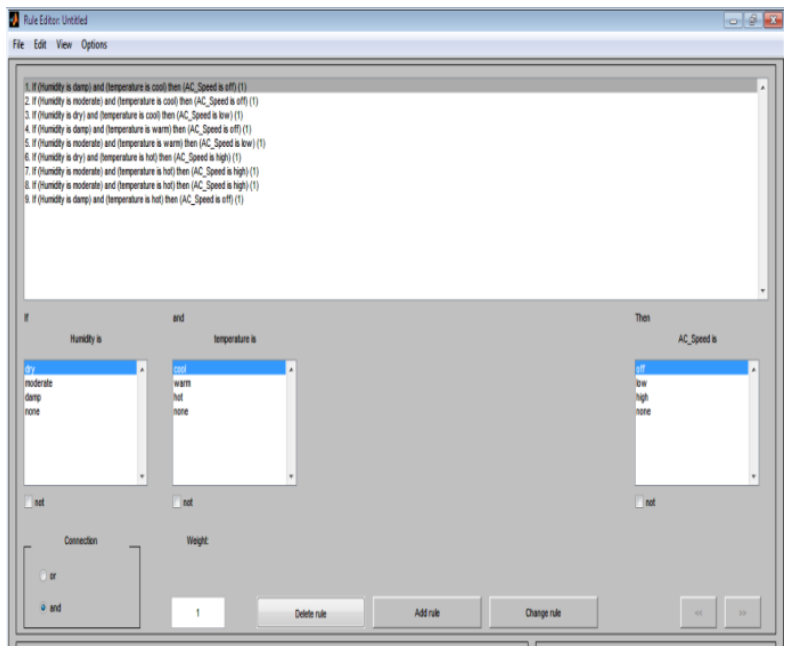

Figure 4. 9 Rules editor

Figure 5.4. Shows the rule editor is MATLAB widow used for insert the input rules to the fuzzy simulator thus block having input, output and selection tools. We select three conditions for each sensor and three output condition which produced 9 rules. 
Vol. 6, Issue 1, January 2017

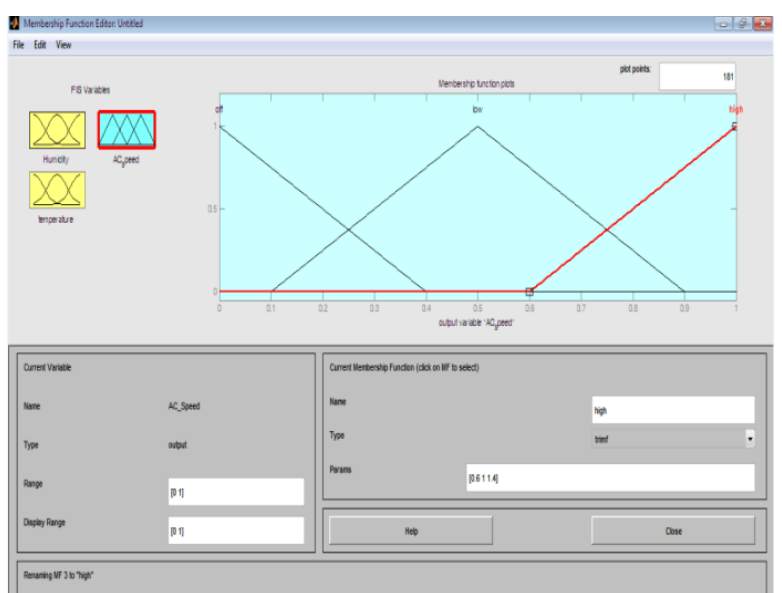

Figure 5. Membership Function Editor

As in the figure 5 the Membership Function Editor used to view the member ship value and the conditions of output.

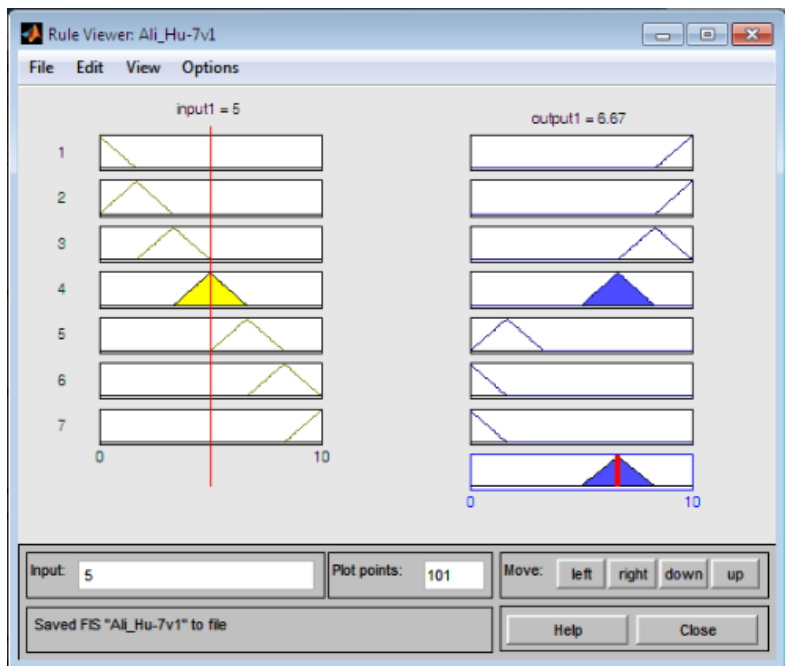

Figure 6. Rule viewer

As in figure 6 Rule is MATLAB widows used for viewing the rule value and the response of the fuzzy controller according to specific input.

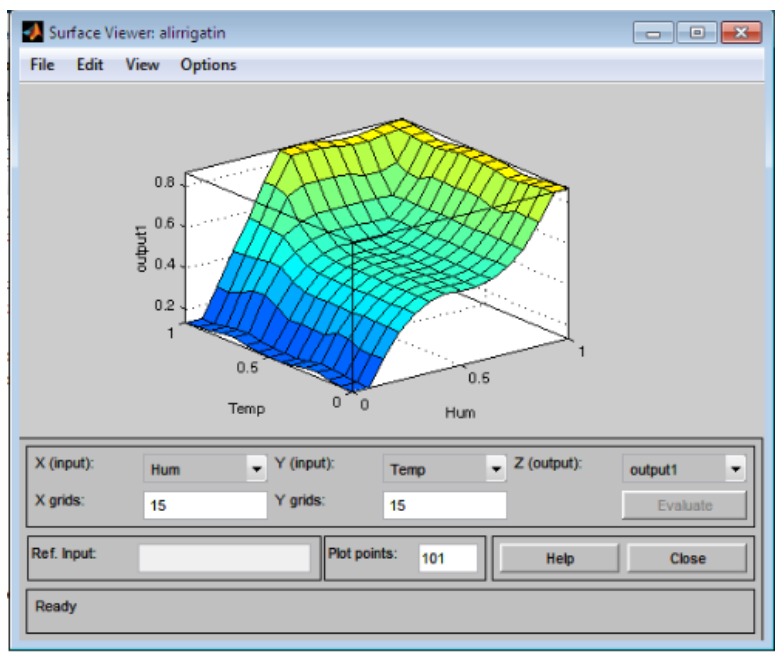

Figure 7. Surface viewer
Shows the relation between the inputs temperature and humidity and the output water controlled for irrigation.

\section{SIMULATION RESULT}

The fuzzy controller simulated by MATLAB as in figure 8 signal taken as random number connected to feedback signal with summing point, temp signal interred through transfer function and humidity through gain 2 and followed via transfer functions1, the output for control signal shows in figure

\section{Mamdani Fuswy controller, with two inputs}

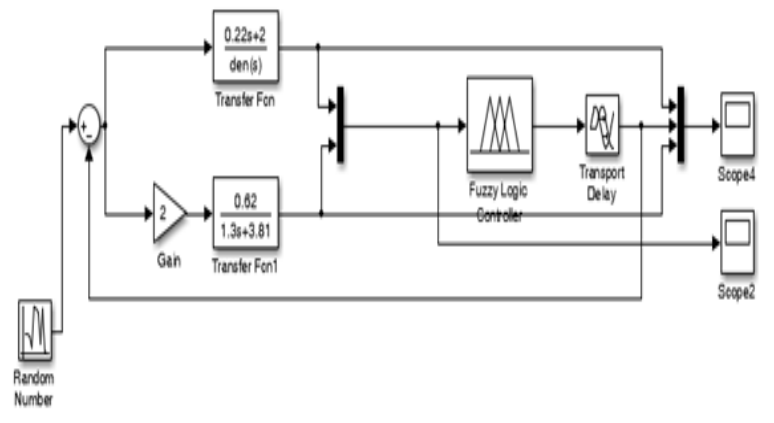

Figure 8. Fuzzy controllers with two inputs temp and humidity

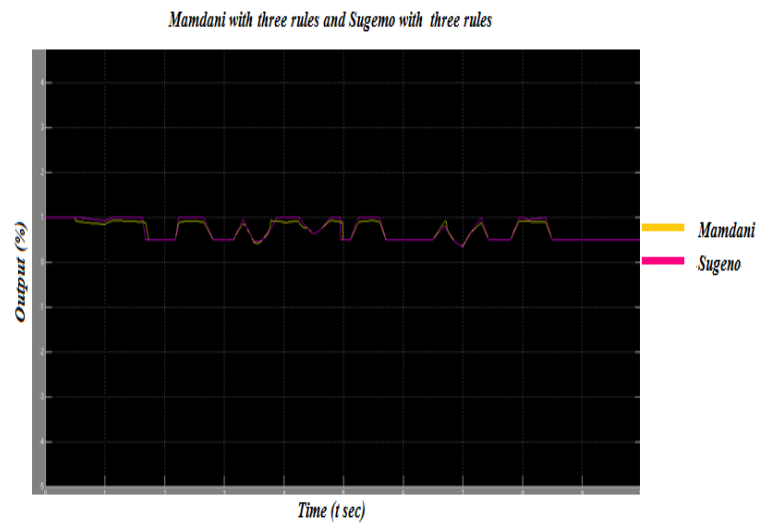

Figure 9. Mamdain and Sugeno controllers with three memberships

Figure 5.14. Shows the output of tow controller each with three memberships the first one is designed via Mamdani method (yellow line) and the second designed via Sugeno Method (pink line)

\section{CONCLUSION}

This research project was developed to implementing irrigation control the key parameters involved in fuzzy logic controller, Mamdani and Sugeno algorithms, a photo cell water pumping system the irrigation of the field through tanks by using control valves. Parameters of interest were irrigation control, fuzzy logic controller 
design, Simulink Control, solar radiation, photovoltaic electrical output, and water flow output. Field research was carried out on Khartoum Sudan, the data used for irrigation controller collected via Soba weather station (Sudan University, college forestry and range science), from August 2011 to May 2013.

\section{REFERENCES}

[1] Carolyn H.1, Jagath E.2 and Pierre R.1"WIRELESS SOIL MOISTURE SENSOR NETWORKS FOR PRECISION IRRIGATION SCHEDULING" Landcare Research, Gerald Street, Lincoln, New Zealand 2012

[2] Suraj S.Avatade1, Prof.S. P. Dhanure2," Irrigation System Using a Wireless Sensor Network and GPRS"

[3] Oliver 1. Iliev1, Pavle Sazdov1, Ahmad Zakeri2, "a fuzzy logic based controller for integrated control of protected cultivation", facta universitatis Series: Automatic Control and Robotics Vol. 11, No 2, 2012,

[4] Nasri Sulaiman, Zeyad Assi Obaid, Member, IACSIT, M. H. Marhaban and M. N. Hamidon, "FPGA-Based Fuzzy Logic: Design and Applications - a Review", IACSIT International Journal of Engineering and Technology Vol.1, No.5, December, 2009.

[5] Faraz Khan1, Faizan Shabbir1 and Zohaib Tahir1, "a fuzzy approach for water security in irrigation system using wireless sensor network", School of Electrical Engineering, the University of Faisalabad Pakistan, Sci.Int.(Lahore),26(3),1065-1070,2014

[6] Utku Ataç, "A fuzzy logic approach for the design of an expert system", Journal of Aviation Management and Education, Maslak, stanbul, Turkey

[7] Liai Gao, Meng Zhang," An Intelligent Irrigation System Based on Wireless Sensor Network and Fuzzy Control", JOURNAL OF NETWORKS, VOL. 8, NO. 5, MAY 2013

[8] *AWATI J.S., **PATIL V.S.," Automatic Irrigation Control by using wireless sensor networks", Journal of Exclusive Management Science - June 2012-Vol 1 Issue 6 - ISSN 2277 - 5684 